\title{
Novel optical properties and induced magnetic moments in Ru-doped hybrid improper ferroelectric $\mathrm{Ca}_{3} \mathrm{Ti}_{2} \mathrm{O}_{7}$
}

\author{
Xingxing $\mathrm{WU}^{a}$, Shouyu WANG ${ }^{b, *}$, Winnie WONG-NG ${ }^{c}$, Qiang GU ${ }^{a}$, \\ Yao JIANG ${ }^{a}$, Chao $\mathrm{WANG}^{a}$, Shuang $\mathrm{MA}^{b}$, Weifang $\mathrm{LIU}^{a, *}$ \\ ${ }^{a}$ Tianjin Key Laboratory of Low Dimensional Materials Physics and Preparing Technology, \\ School of Science, Tianjin University, Tianjin 300072, China \\ ${ }^{b}$ College of Physics and Material Science, Tianjin Normal University, Tianjin 300074, China \\ ${ }^{c}$ Materials Measurement Science Division, National Institute of Standards and \\ Technology, Gaithersburg, Maryland 20899, USA
}

Received: March 7, 2020; Revised: September 5, 2020; Accepted: September 9, 2020

(c) The Author(s) 2020.

\begin{abstract}
Hybrid improper ferroelectric $\mathrm{Ca}_{3} \mathrm{Ti}_{2} \mathrm{O}_{7}$ and $\mathrm{Ca}_{3} \mathrm{Ti}_{1.9} \mathrm{Ru}_{0.1} \mathrm{O}_{7}$ ceramics were successfully synthesized by conventional solid-state reaction method. Two strongest diffraction peaks located around $2 \theta=33^{\circ}$ shifted towards the lower angle region with $\mathrm{Ru}$ substitution, reflecting structure variation. Grain growth and higher oxygen vacancy concentration after doping resulted in a reduction in the coercive field about $20 \mathrm{kV} / \mathrm{cm}$. Optical bandgap estimated by UV-vis diffuse reflectance (DR) spectrum and X-ray photoelectron spectroscopy (XPS) valence band spectra showed a decreasing trend due to the existence of impurity energy level upon Ru doping, which was consistent with the results of first-principles calculations. The origin of the unexpected induced magnetic moments in $\mathrm{Ru}$-dope $\mathrm{Ca}_{3} \mathrm{Ti}_{2} \mathrm{O}_{7}$ is also discussed.
\end{abstract}

Keywords: oxides; electronic materials; optical properties; X-ray diffraction; defects; lectronic structure; ferroelectricity

\section{Introduction}

In recent years, hybrid improper ferroelectricity (HIF) has been investigated extensively due to its promising applications in creating room-temperature multiferroic materials with strong magnetoelectric coupling [1-3]. The term "hybrid" improper ferroelectricity is used to describe the two kinds of octahedron rotations, and the main feature of HIF is the combination of coherent

\footnotetext{
* Corresponding authors.

E-mail: S. Wang, shouyu.wang@yahoo.com;

W. Liu,wfliu@tju.edu.cn
}

oxygen octahedral rotation $\left(\mathrm{a}^{0} \mathrm{a}^{0} \mathrm{c}^{+}\right.$in Glazer's notation) and tilting $\left(\mathrm{a}^{-} \mathrm{a}^{-} \mathrm{c}^{0}\right)[4,5]$. Researchers have proposed that HIF widely exits in artificial superlattices such as $\mathrm{SrTiO}_{3} / \mathrm{PbTiO}_{3}$ and Ruddlesden-Propper structure $\left(\mathrm{A}_{n+1} \mathrm{~B}_{n} \mathrm{O}_{3 n+1}, \mathrm{RP}\right)$ [1,2,6-9]. Liu et al. [5] and Oh et al. [10] also demonstrated experimentally that HIF existing in the RP structures at room temperature. RP structure has become the focus for HIF research since the octahedral tilting and rotation exist extensively in these materials.

$\mathrm{Ca}_{3} \mathrm{Ti}_{2} \mathrm{O}_{7}$ is one of the typical RP structures $(n=2)$ with properties including prominent photocatalytic, special luminescence, and significant hybrid improper 
ferroelectric properties [8,11-16]. Recently, researchers are working to improve the ferroelectric properties by doping or substitution. Li et al. [17] studied the preferential occupation of A-site substitution and proposed isovalent substitution could enhance ferroelectricity. Huang et al. [18] successfully reduced the coercive field by doping $\mathrm{Na}$ ions at the A-site and found a novel reversible diode effect. So far, most investigators have focused their research on the substitution of A-site, and only a handful of studies were focused on B-site doping. Liu et al. [19] proposed theoretically that B-site doped $\mathrm{Ca}_{3} \mathrm{Ti}_{2} \mathrm{O}_{7}$ reduces polarization with decreased tolerance factor, and they also found the first-order phase transition temperatures of $\mathrm{Ca}_{3} \mathrm{Ti}_{2-x} \mathrm{Mn}_{x} \mathrm{O}_{7}(x=0$, $0.05,0.1,0.15)$ decrease linearly with increasing $\mathrm{Mn}$ doping concentration [5]. In 2012, Gong et al. [20] experimentally confirmed that $\mathrm{Ru}^{4+}$ is a magnetic ion that enhances ferromagnetic properties in $\mathrm{Bi}_{0.9} \mathrm{La}_{0.1} \mathrm{FeO}_{3}$ ceramics. However, the influence of ferroelectric and optical properties through B-site substitution has not been extensively studied experimentally.

In this work, we chose $\mathrm{Ru}^{4+}$ as the $\mathrm{B}$-site dopant and prepared $\mathrm{Ca}_{3} \mathrm{Ti}_{2} \mathrm{O}_{7}$ and $\mathrm{Ca}_{3} \mathrm{Ti}_{1.9} \mathrm{Ru}_{0.1} \mathrm{O}_{7}$ ceramics by solid-state synthesis technique. The coercive field was effectively reduced with $\mathrm{Ru}$ substitution, suggesting $\mathrm{Ca}_{3} \mathrm{Ti}_{1.9} \mathrm{Ru}_{0.1} \mathrm{O}_{7}$ is more favorable for practical applications. Interestingly, the magnetization hysteresis loop shows obviously hysteresis after $\mathrm{Ru}$ doping and the spin-up and spin-down density of state (DOS) became asymmetric, which indicates weak ferromagnetism was induced, thereby making it possible to achieve room temperature multiferroic materials.

\section{Experimental}

\section{1 Preparation of the samples}

Powders $\mathrm{Ca}_{3} \mathrm{Ti}_{2} \mathrm{O}_{7}$ and $\mathrm{Ca}_{3} \mathrm{Ti}_{1.9} \mathrm{Ru}_{0.1} \mathrm{O}_{7}$ were synthesized by a conventional solid-state reaction method in air. Appropriate amounts of $\mathrm{CaCO}_{3}(99.99 \%), \mathrm{TiO}_{2}(99.99 \%)$, and ruthenium oxide hydrate (ruthenium content of $75 \%$ ) were chosen as starting materials and were thoroughly grounded with alcohol and agate balls for $10 \mathrm{~h}$. The mixture was preheated at $1000{ }^{\circ} \mathrm{C}$ for $10 \mathrm{~h}$ and reground to obtain the desired powders. Finally, the powders were pressed into cylindrical compacts under uniaxial compression and sintered at 1450 and $1460{ }^{\circ} \mathrm{C}$ in air for $30 \mathrm{~h}$ to obtain the dense $\mathrm{Ca}_{3} \mathrm{Ti}_{2} \mathrm{O}_{7}$ and $\mathrm{Ca}_{3} \mathrm{Ti}_{1.9} \mathrm{Ru}_{0.1} \mathrm{O}_{7}$ ceramics.

\section{2 Characterizations of the samples}

Crystal structure analysis of the samples was carried out by X-ray diffraction (XRD, Rigaku D/MAX-2500 diffractometer with $\mathrm{Cu} \mathrm{K} \alpha$ radiation). Microstructures were investigated by scanning electron microscopy (SEM) using a model SU8010 field-emission scanning electron microscope (Hitachi Co., Tokyo, Japan). To analyze the chemical states of the constituents and the content of surface elements, X-ray photoelectron spectroscopy (XPS) was performed using a PHI1600 spectrometer (U1vac-Phi Co., Chigasaki, Kanagawa, Japan). Silver was placed on both sides of ceramics for the electrical property testing, using an Axiacct TF2000 ferroelectric analyzer (aixACCT Co., Aachen, Germany). $\mathrm{UV}$-vis diffuse reflectance (DR) spectrums were recorded with a UV-3600UV-VIS-NIR spectrophotometer (Shimadzu Co., Tokyo, Japan). The magnetization hysteresis $(M-H)$ loops of the samples at room temperature were made with a SQUID-VSM magnetic property measurement system (Quantum Design Co., San Diego, CA, USA). First-principles calculations were performed using Vienna $a b$ initio Simulation Package (VASP) with projector augmented wave (PAW) potentials. The exchange-correlation interaction was treated by PerdewBurke-Ernaerhof (GGA-PBE) with a plane wave energy cut off of $500 \mathrm{eV}$. To study the change of bandgap, the unit cell with $5 \times 1 \times 5$ Monkhorst-Pack k-point mesh was used to calculate density of state (DOS) and differential charge density on $\mathrm{Ca}_{3} \mathrm{Ti}_{2} \mathrm{O}_{7}$ and $\mathrm{Ru}$-doped samples.

\section{Results and discussion}

\section{1 Crystal structure characterization}

The XRD patterns of $\mathrm{Ca}_{3} \mathrm{Ti}_{2} \mathrm{O}_{7}$ and $\mathrm{Ca}_{3} \mathrm{Ti}_{1.9} \mathrm{Ru}_{0.1} \mathrm{O}_{7}$ after Rietveld refinement process using FULLPROF software are illustrated in Fig. 1(a) [21]. All peaks in the diffraction patterns could be matched perfectly with those of $\mathrm{Ca}_{3} \mathrm{Ti}_{2} \mathrm{O}_{7}$ (space group $A 2_{1}$ am (No. 36)) [22]. Absence of additional peaks indicates $\mathrm{Ru}$ atoms replaced $\mathrm{Ti}$ atoms successfully. It is obvious that the two strongest peaks located at around $2 \theta=33^{\circ}$ shifted towards the lower angle region with the Ru doping (Fig. 1(b)), implying changes of the unit cell parameters. Detailed analysis of the structural parameters using the Rietveld refinement is given in Table 1. It can be seen that $a, b$, and $V$ increased with Ru substitution, which is consistent with the theoretical prediction since the ionic radius of 

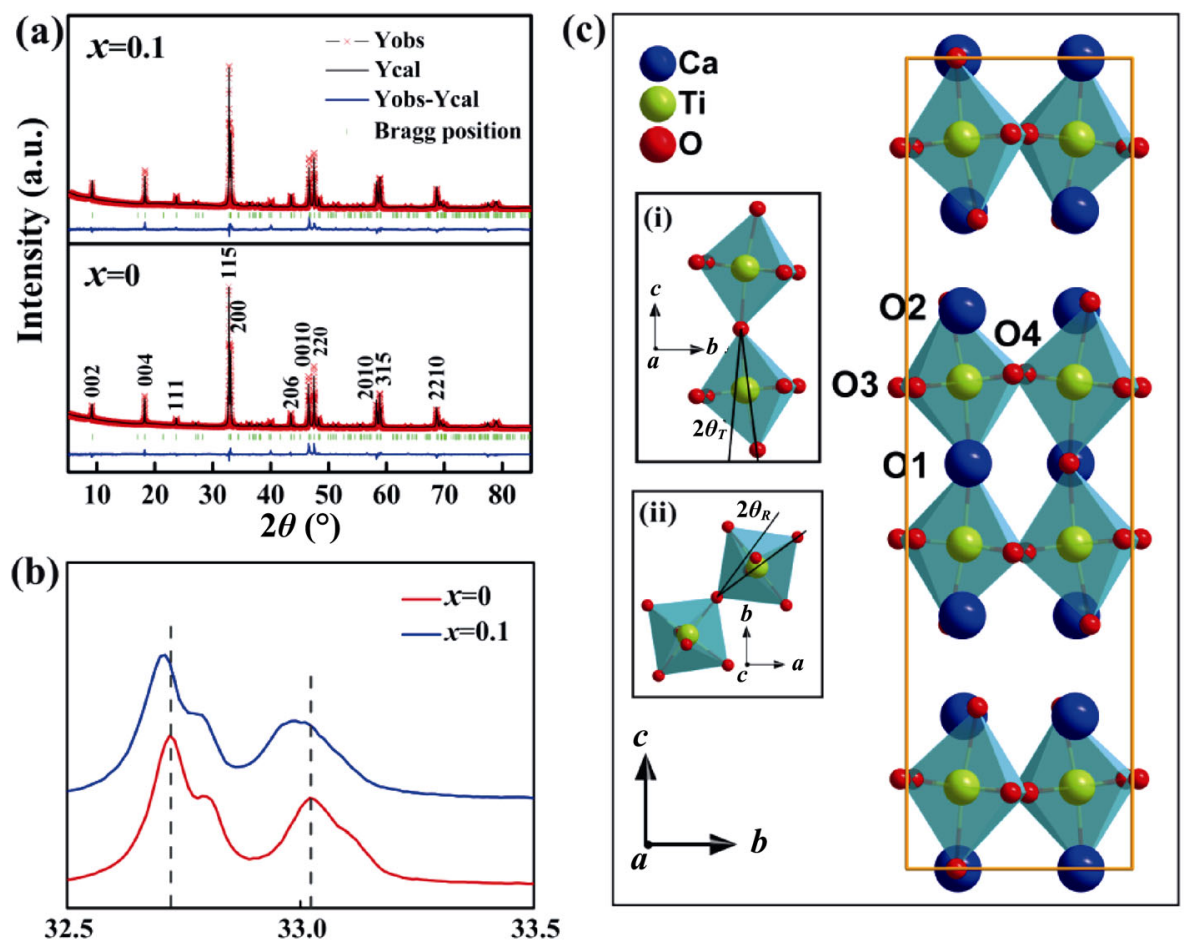

Fig. 1 (a) Rietveld refined XRD patterns of $\mathrm{Ca}_{3} \mathrm{Ti}_{2-x} \mathrm{Ru}_{x} \mathrm{O}_{7}(x=0,0.1)$ samples. (b) Enlarged views of the diffraction peaks located at about $33^{\circ}$. (c) Crystal structure of $\mathrm{Ca}_{3} \mathrm{Ti}_{2} \mathrm{O}_{7}$. The upper insets are the oxygen octahedral tilt angle $\theta_{\mathrm{T}}$ and oxygen octahedral rotation angle $\theta_{\mathrm{R}}$ respectively.

Table 1 Structure parameters obtained from Rietveld refinement of $\mathrm{Ca}_{3} \mathrm{Ti}_{2} \mathrm{O}_{7}$ and $\mathrm{Ca}_{3} \mathrm{Ti}_{1.9} \mathbf{R u}_{0.1} \mathrm{O}_{7}$

\begin{tabular}{ccccccccc}
\hline$x$ & $a(\AA)$ & $b(\AA)$ & $c(\AA)$ & $V\left(\AA^{3}\right)$ & Ti-O1/Ti-O2 & Ti-O3/Ti-O4 & Ti-O1-Ti & $\chi^{2}$ \\
\hline 0 & $5.42302(14)$ & $5.41764(14)$ & $19.51445(41)$ & 573.334 & $1.9872 / 1.9588$ & $1.9686 / 1.9700$ & 159.641 & 3.55 \\
0.1 & $5.42913(13)$ & $5.42143(13)$ & $19.50931(39)$ & 574.230 & $1.9868 / 1.9584$ & $1.9705 / 1.9719$ & 159.614 & 3.20 \\
\hline
\end{tabular}

$\mathrm{Ru}$ (radius $=0.620 \AA$ ) [23] is slightly larger than that of $\mathrm{Ti}$ (radius $=0.605 \AA$ ) [24]. However, the lattice shrinking along $c$ direction is likely caused by the decrease of the vertical Ti-O1 (O2) bond lengths and $\mathrm{Ti}-\mathrm{O} 1-\mathrm{Ti}$ bond angles. The elongation of the in-plane Ti-O3 (O4) bond length can be attributed to the pressure of vertical plane and expanded volume. The variation of bond lengths and bond angle reflects the distortion of the oxygen octahedra. The crystal structures of $\mathrm{Ca}_{3} \mathrm{Ti}_{2-x} \mathrm{Ru}_{x} \mathrm{O}_{7}(x=0,0.1)$ ceramics projected on different planes are shown in the insets of Fig. 1(c). For $\mathrm{Ca}_{3} \mathrm{Ti}_{2} \mathrm{O}_{7}$, the oxygen octahedral rotation angle $\left(\theta_{\mathrm{R}}\right)$ and tilt angle $\left(\theta_{\mathrm{T}}\right)$ are $9.846^{\circ}$ and $10.180^{\circ}$, respectively. While for $\mathrm{Ca}_{3} \mathrm{Ti}_{1.9} \mathrm{Ru}_{0.1} \mathrm{O}_{7}$, the values of $\theta_{\mathrm{R}}$ and $\theta_{\mathrm{T}}$ are $9.842^{\circ}$ and $10.193^{\circ}$, respectively. According to the formula: $P \propto \alpha Q_{\mathrm{R}} Q_{\mathrm{T}}$ (where $P$ is spontaneous polarization, $\alpha$ represents the coupling coefficient, and $Q_{\mathrm{R}}$ and $Q_{\mathrm{T}}$ are amplitude of rotation and tilt respectively) [25]. The angle of tilt mode increased after $\mathrm{Ru}$ doping, so the spontaneous polarization may be improved in $\mathrm{Ca}_{3} \mathrm{Ti}_{1.9} \mathrm{Ru}_{0.1} \mathrm{O}_{7}$.

\section{2 Ferroelectricity research}

The most important feature of ferroelectric materials is their ability to reverse their polarization state under the applied electric field, appearing as a hysteresis loop with a corresponding electric field $(P-E) . P-E$ loop can be easily affected by temperature, and magnitude and frequency of the applied electric field [26]. Key ferroelectric parameters, such as the remnant polarization $P_{\mathrm{r}}$ and coercive electric field $E_{\mathrm{c}}$ are obtained from these measurements. However, since the polarization of ferroelectrics is not saturated, the uncertainty of the coercive electric field obtained from the $P-E$ loop is somewhat greater. Thus, displacement current verses electrical field $(I-E)$ loops were also shown in the figures. The displacement current involves three parts: leakage current, ferroelectric domain switching, and dielectric displacement. As shown in Figs. 2(a) and 
2(b), the current exhibits an obvious peak under Dynamically Hysteresis Method (DHM), which indicates domain switching and confirms its ferroelectric characteristic [27]. Since the positive up negative down (PUND) method can remove the nonhysteretic components, $P-E$ and $I-E$ loops of $\mathrm{Ca}_{3} \mathrm{Ti}_{2-x} \mathrm{Ru}_{x} \mathrm{O}_{7}(x=$ $0,0.1)$ ceramics were obtained by PUND measurement and shown in Figs. 2(c) and 2(d). The coercive field decreased from about 120 to $100 \mathrm{kV} / \mathrm{cm}$ after $\mathrm{Ru}$ doping. The remnant polarization values of the $\mathrm{Ca}_{3} \mathrm{Ti}_{2} \mathrm{O}_{7}$ and $\mathrm{Ca}_{3} \mathrm{Ti}_{1.9} \mathrm{Ru}_{0.1} \mathrm{O}_{7}$ samples are 1.6 and $4.4 \mu \mathrm{C} / \mathrm{cm}^{2}$ respectively, which indicate the enhancement of polarization via $\mathrm{Ru}$ doping. The result is consistent with the above structure analysis.

\section{3 Microstructure characterization}

In order to analyze the cause of reduced coercive field in $\mathrm{Ca}_{3} \mathrm{Ti}_{1.9} \mathrm{Ru}_{0.1} \mathrm{O}_{7}$, the grain size of this material was characterized by SEM. The SEM images and corresponding size distribution histogram of both samples are shown in Fig. 3. It can be seen that both samples show approximate flake-like shape grains and the
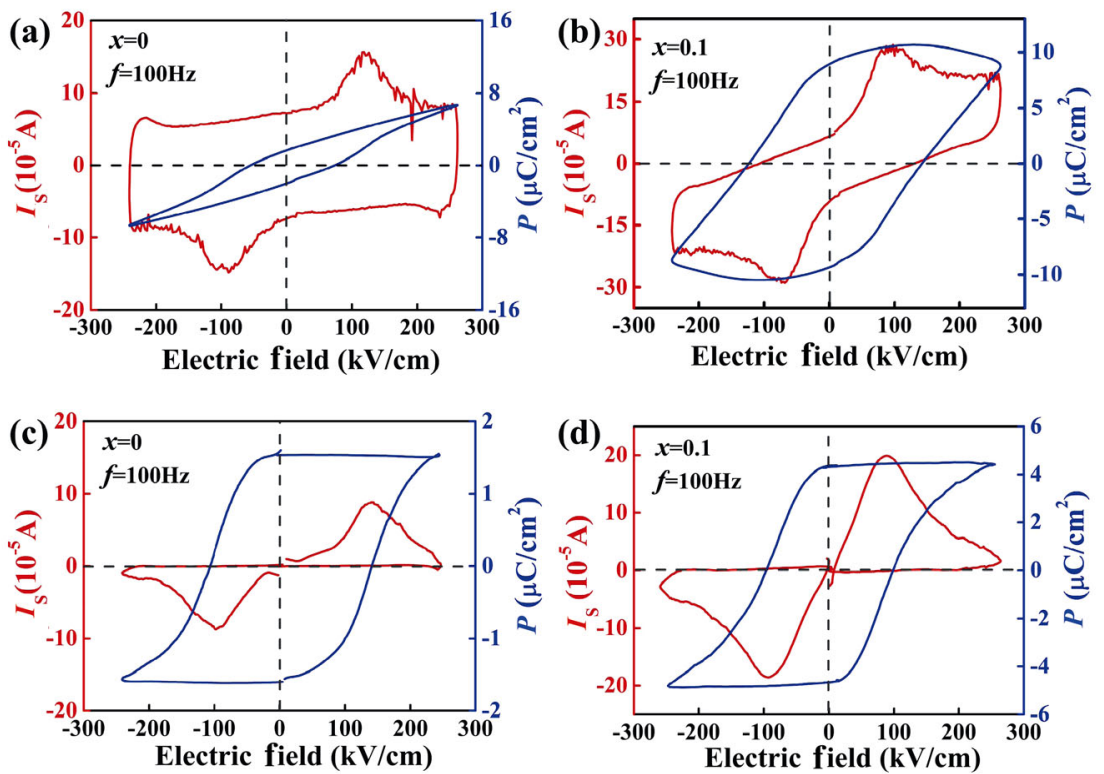

Fig. $2 P-E$ loops and displacement current recorded at frequency of $100 \mathrm{~Hz}$ in DHM mode for (a) $\mathrm{Ca}_{3} \mathrm{Ti}_{2} \mathrm{O}_{7},\left(\right.$ b) $\mathrm{Ca}_{3} \mathrm{Ti}_{1.9} \mathrm{Ru}_{0.1} \mathrm{O}_{7}$. $P-E$ loops of $\mathrm{Ca}_{3} \mathrm{Ti}_{2} \mathrm{O}_{7}$ and $\mathrm{Ca}_{3} \mathrm{Ti}_{1.9} \mathrm{Ru}_{0.1} \mathrm{O}_{7}$ ceramics obtained by PUND measurement for (c) and (d), respectively.
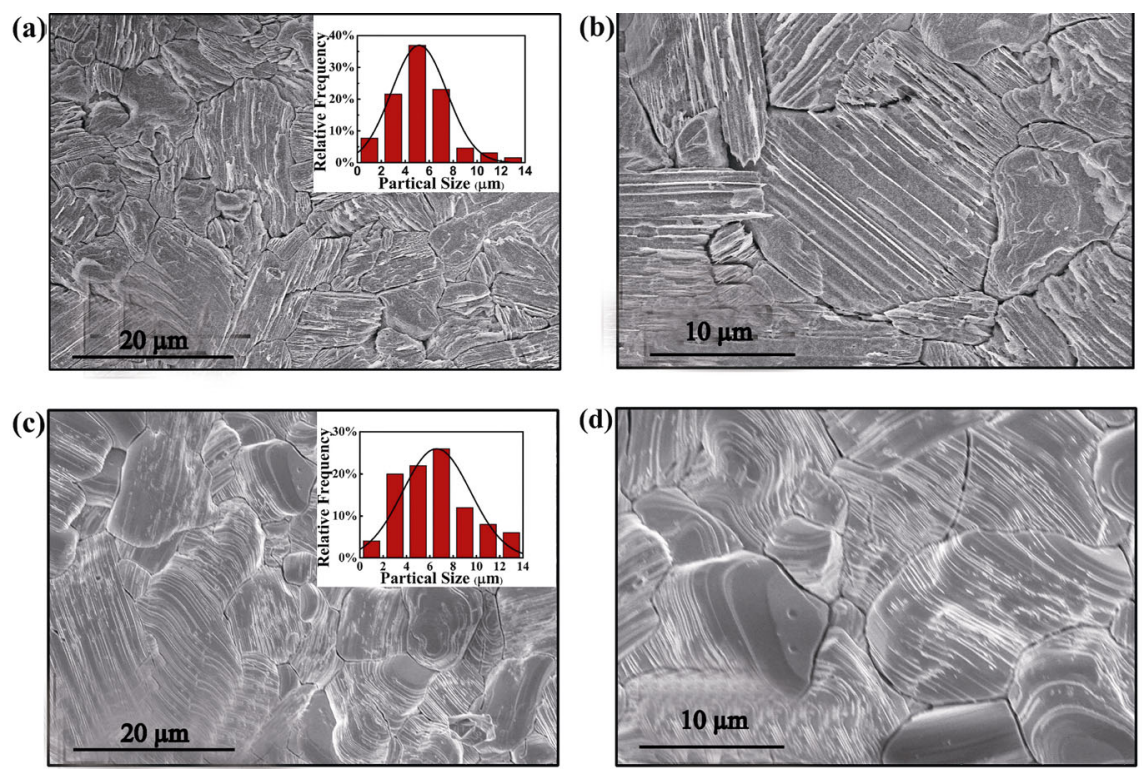

Fig. 3 SEM images of $(a, b) \mathrm{Ca}_{3} \mathrm{Ti}_{2} \mathrm{O}_{7}$ ceramic and (c, d) $\mathrm{Ca}_{3} \mathrm{Ti}_{1.9} \mathrm{Ru}_{0.1} \mathrm{O}_{7}$ ceramic. The upper insets are the corresponding statistic particle size distribution of $\mathrm{Ca}_{3} \mathrm{Ti}_{2-x} \mathrm{Ru}_{x} \mathrm{O}_{7}(x=0,0.1)$ samples. 
thickness varies from 1 to $14 \mu \mathrm{m}$, with the average size increased from 5.33 to $6.85 \mu \mathrm{m}$ after Ru doping. In ferroelectric ceramics, the crystallite grains are randomly oriented and contain multiple ferroelectric domains. When domains in a grain attempt to switch under an external electric field, they are constrained by adjacent grains of different orientations [27,28]. This causes the $E_{\mathrm{c}}$ values of ceramics with smaller grains much higher than ceramics with large grains. Besides, the lager grain size of $\mathrm{Ca}_{3} \mathrm{Ti}_{1.9} \mathrm{Ru}_{0.1} \mathrm{O}_{7}$ ceramic can effectively improve the ferroelectric polarization due to fewer grain boundaries in the same area, which resulted in weakened influence of the domain pinning effect $[29,30]$.

\section{4 Valence state and element content analysis}

Oxygen vacancy concentration is another factor affecting the coercive field. XPS measurements were carried out and the spectra of $\mathrm{Ca} 2 \mathrm{p}, \mathrm{O} 1 \mathrm{~s}$, and Ti $3 \mathrm{~d}$ core level fitted by Lorentzian-Gaussian functions are presented in Fig. 4, where the core level binding energies were aligned with respect to $\mathrm{C} 1 \mathrm{~s}$ peak $(284.6 \mathrm{eV})$. The $\mathrm{O} 1 \mathrm{~s}$ core level regions are fitted to 3 peaks at about 529.3, 531.3, and $532.4 \mathrm{eV}$ in Fig. 4(b). The first line (red) is attributed to the oxygen present in the lattice and the second line (blue) is related to the oxygen deficient regions $[31,32]$. The last one (green) corresponds to adsorbed molecular water [33]. Since oxygen vacancy plays an important role in modifying physical properties and optical properties, we elucidate the variations of defects by using a semiquantitative formula. The relative concentration of lattice oxygen could be described by the following formula [34]:

$$
C_{x}=\frac{I_{x}}{S_{x}} / \sum_{i} \frac{I_{i}}{S_{i}}
$$

where $C_{x}$ is the concentration of the measured atom, $I_{x}$ is the intensity of the peak corresponding to the measured elements, $S_{x}$ is the sensitivity factor of the measured elements, and $S_{i}$ is that of the $i$ th element. The calculated atom ratio of $\mathrm{O} / \mathrm{Ca}$ in $\mathrm{Ca}_{3} \mathrm{Ti}_{2} \mathrm{O}_{7}$ sample is 2.06, which is smaller than the stoichiometric ratio of 2.33. It is well known that calcination will introduce oxygen vacancies at high temperature. For $\mathrm{Ca}_{3} \mathrm{Ti}_{1.9} \mathrm{Ru}_{0.1} \mathrm{O}_{7}$ sample, the atom ratio of $\mathrm{O} / \mathrm{Ca}$ is calculated to be 1.90, indicating more oxygen vacancies are introduced after the $\mathrm{Ru}$ doping. The domain cores were more likely to be formed around defective regions. As the electric field is enhanced, the domain walls begin to move in the direction of the electric field, while these walls also expand widthwise [35]. Thus, the domain volume fraction along the direction of the electric field is increased and the opposite domain volume fraction is reduced until it becomes a single domain, which explains the decrease of coercive field by Ru doping. The fitted Ti $2 p$ spectra are shown in Fig. 4(c), where binding energy peaks of Ti 2p3/2 located at about 457.8 and $456.8 \mathrm{eV}$ correspond to the $\mathrm{Ti}^{4+}$ and $\mathrm{Ti}^{3+}$ respectively [36]. For $\mathrm{Ca}_{3} \mathrm{Ti}_{2} \mathrm{O}_{7}$ and $\mathrm{Ca}_{3} \mathrm{Ti}_{1.9} \mathrm{Ru}_{0.1} \mathrm{O}_{7}$, the ratio of $\mathrm{Ti}^{3+} / \mathrm{Ti}^{4+}$ is calculated as 0.18 and 0.26 , which demonstrates the concentration of $\mathrm{Ti}^{3+}$ increases with $\mathrm{Ru}$ doping. Some tetravalent titanium ions are converted to trivalent during the preparation process and the tendency is enhanced further after doping with $\mathrm{Ru}$, which can be described as follow:

$$
\mathrm{Ti}^{4+}+\mathrm{e}^{\prime} \rightarrow \mathrm{Ti}^{3+}
$$

The combination of trivalent titanium and lattice oxygen makes more oxygen vacancy be produced. This process can be illustrated by the following steps:

$$
\begin{gathered}
2 \mathrm{Ti}^{3+}+3 \mathrm{O}^{2-} \rightarrow 2\left(\mathrm{Ti}_{\mathrm{Ti}^{4+}}\right)^{\prime}+2 \mathrm{~h}^{\bullet}+3 \mathrm{O}_{\mathrm{O}}^{\times} \\
2 \mathrm{O}^{2-}+4 \mathrm{~h}^{\bullet} \rightarrow \mathrm{O}_{2} \uparrow+\mathrm{V}_{\mathrm{O}}
\end{gathered}
$$

Here, $h^{\bullet}$ denotes hole and $V_{O}$ represents oxygen vacancy.

The leakage current density versus applied electric field $(J-E)$ is given in Fig. 4(d). One notes that the leakage current is increased significantly after $\mathrm{Ru}$ doping, which can be attributed to the influence of oxygen vacancies whose main function is to introduce carriers. The main process can be expressed by

$$
\begin{aligned}
& \mathrm{V}_{\mathrm{O}} \rightarrow \mathrm{V}_{\mathrm{O}}^{\cdot}+\mathrm{e}^{\prime} \\
& \mathrm{V}_{\mathrm{O}}^{\cdot} \rightarrow \mathrm{V}_{\mathrm{O}}^{\cdot \bullet}+\mathrm{e}^{\prime}
\end{aligned}
$$

Thus, $\mathrm{Ru}$ substitution increases the ionized oxygen vacancy $\left(\mathrm{V}_{\mathrm{O}}^{*}\right.$ or $\left.\mathrm{V}_{\mathrm{O}}^{*}\right)$, the conducting electron $\left(\mathrm{e}^{\prime}\right)$, and the hole $\left(\mathrm{h}^{\bullet}\right)$. The combination of these species is eventually, responsible for the high leakage current in $\mathrm{Ca}_{3} \mathrm{Ti}_{1.9} \mathrm{Ru}_{0.1} \mathrm{O}_{7}$.

\section{5 Optical and magnetic property analysis}

It is common knowledge that the doping will influence optical properties; therefore, the optical properties of the $\mathrm{Ca}_{3} \mathrm{Ti}_{2-x} \mathrm{Ru}_{x} \mathrm{O}_{7}(x=0,0.1)$ were obtained by UV-vis DR spectra at room temperature (Fig. 5(a)). The data were collected with reference to a $\mathrm{BaSO}_{4}$ standard. We note that $\mathrm{Ca}_{3} \mathrm{Ti}_{2} \mathrm{O}_{7}$ has strong absorption 

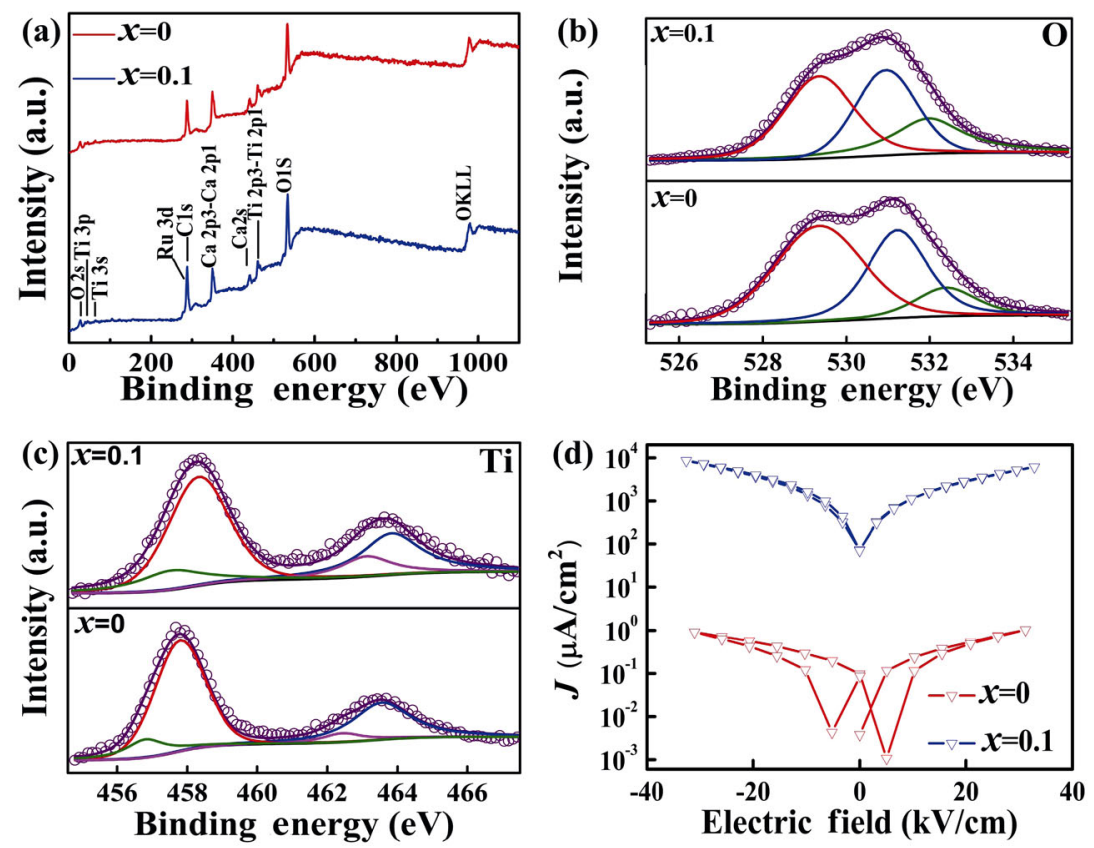

Fig. 4 XPS spectra of (a) full spectrum, (b) $\mathrm{O} 1 \mathrm{~s}$, and (c) Ti $2 p$ for $\mathrm{Ca}_{3} \mathrm{Ti}_{2-x} \mathrm{Ru}_{x} \mathrm{O}_{7}(x=0,0.1)$ samples. (d) Leakage current data for $\mathrm{Ca}_{3} \mathrm{Ti}_{2} \mathrm{O}_{7}$ and $\mathrm{Ca}_{3} \mathrm{Ti}_{1.9} \mathrm{Ru}_{0.1} \mathrm{O}_{7}$.

in the range of 300-400 $\mathrm{nm}$; however, there are two absorption edges in the $\mathrm{Ca}_{3} \mathrm{Ti}_{1.9} \mathrm{Ru}_{0.1} \mathrm{O}_{7}$ sample, and the band gap of $\mathrm{Ca}_{3} \mathrm{Ti}_{1.9} \mathrm{Ru}_{0.1} \mathrm{O}_{7}$ reduced greatly relative to that of $\mathrm{Ca}_{3} \mathrm{Ti}_{2} \mathrm{O}_{7}$. Figure $5(\mathrm{~b})$ gives the valence band XPS of $\mathrm{Ca}_{3} \mathrm{Ti}_{2-x} \mathrm{Ru}_{x} \mathrm{O}_{7}(x=0,0.1)$. The valence band maximum was estimated to be around $1.39 \mathrm{eV}$ for $\mathrm{Ca}_{3} \mathrm{Ti}_{2} \mathrm{O}_{7}$, while $\mathrm{Ca}_{3} \mathrm{Ti}_{1.9} \mathrm{Ru}_{0.1} \mathrm{O}_{7}$ showed notable differences: the main absorption is located at $0.54 \mathrm{eV}$, whereas an unusual maximum energy associated with the band tail blue-shifts towards the vacuum level at about $-1.52 \mathrm{eV}$. It was reported that in black $\mathrm{TiO}_{2}$ nanoparticles, the band tail is attributed to the defect band formed by oxygen vacancy [37]. Based on this report, we carried out first-principles calculation to verify the contribution of the band tail in $\mathrm{Ca}_{3} \mathrm{Ti}_{1.9} \mathrm{Ru}_{0.1} \mathrm{O}_{7}$.

Field-dependent magnetizations were recorded at room temperature to explore the magnetic properties.
Figure 6 shows the magnetization hysteresis loops of $\mathrm{Ca}_{3} \mathrm{Ti}_{2-x} \mathrm{Ru}_{x} \mathrm{O}_{7}(x=0,0.1)$ with an applied field up to a maximum of $25 \mathrm{kOe}$. The obvious hysteresis after $\mathrm{Ru}$ doping demonstrates the existence of a weak ferromagnetic component, which can be attributed to the special valence electron configuration of Ru ions $\left(4 d^{4}\right)$. In $\mathrm{RuO}_{6}$ octahedron, the $\mathrm{d}$ orbitals of $\mathrm{Ru}^{4+}$ can be divided into two high-level $e_{g}$ orbitals and three lowlevel $t_{2 g}$ orbitals under the influence of ligand field. The electrons in $\mathrm{d}$ orbitals of $\mathrm{Ru}^{4+}$ are preferable to lowspin state occupation and the electron configuration is $\left(t_{2 g}\right)^{4}$, which is consistent with the following theoretical calculation (the magnetic moment of $\mathrm{Ru}$ is calculated to be about $1.37 \mu_{\mathrm{B}}$ ). It has been reported that the magnetism is increased with Ru substitution in varied systems $[38,39]$; therefore $\mathrm{Ru}$ doping is of great significance in improving the magnetic properties of materials.
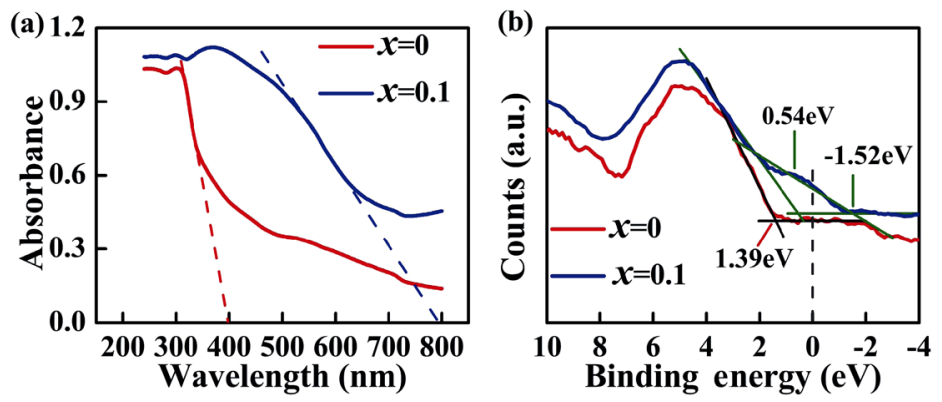

Fig. 5 (a) UV-vis DR spectra of $\mathrm{Ca}_{3} \mathrm{Ti}_{2-x} \mathrm{Ru}_{x} \mathrm{O}_{7}(x=0,0.1)$ samples. (b) XPS valence band spectra for $\mathrm{Ca}_{3} \mathrm{Ti}_{2} \mathrm{O}_{7}$ and $\mathrm{Ca}_{3} \mathrm{Ti}_{1.9} \mathrm{Ru}_{0.1} \mathrm{O}_{7}$ samples. 


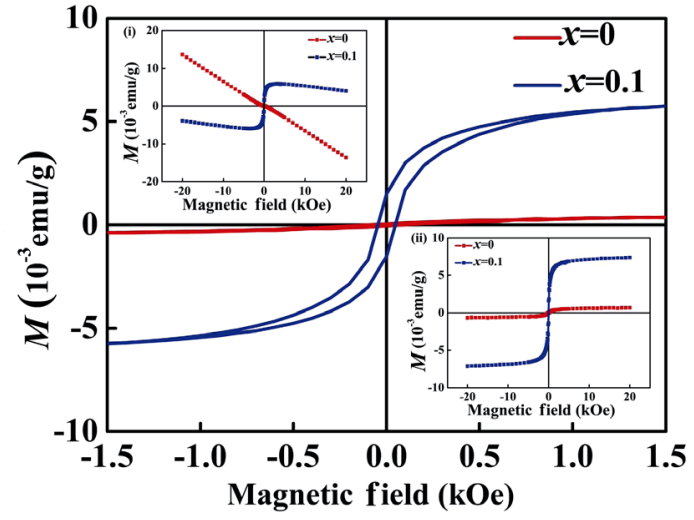

Fig. 6 Field-dependent magnetization hysteresis $(M-H)$ loops of $\mathrm{Ca}_{3} \mathrm{Ti}_{2-x} \mathrm{Ru}_{x} \mathrm{O}_{7}(x=0,0.1)$ ceramics in low field at room temperature. Insets: (i) raw data of $M-H$ loop with an applied field up to a maximum of $25 \mathrm{kOe}$; (ii) $M-H$ loops in which diamagnetism were removed.

\section{6 First-principles calculation}

\subsubsection{DOS analysis}

The first-principles calculation was conducted to analyze the DOS and electronic structure. DOS calculations were performed for two compositions: (i) pure $\mathrm{Ca}_{3} \mathrm{Ti}_{2} \mathrm{O}_{7}$ unit cell and (ii) $\mathrm{Ru}$-doped unite cell (a Ti atom was substituted by a $\mathrm{Ru}$ atom in a unit cell). The results are shown in Figs. 7(a) and 7(b). The valence band is mainly composed of the $\mathrm{O} 2 \mathrm{p}$ states. The conduction band in the range from 2.5 to $4 \mathrm{eV}$ is mainly contributed by the $\mathrm{Ti} 3 \mathrm{~d}$ and $\mathrm{O} 2 \mathrm{p}$ states. Compared with $\mathrm{Ca}_{3} \mathrm{Ti}_{2} \mathrm{O}_{7}$, the impurity energy level appears from -2 to $1 \mathrm{eV}$ in $\mathrm{Ru}$-doped $\mathrm{Ca}_{3} \mathrm{Ti}_{2} \mathrm{O}_{7}$, which is comprised by $\mathrm{Ru} 3 \mathrm{~d}$ and $\mathrm{O} 2 \mathrm{p}$ states and distributes on both sides of the Fermi level. The band gap of Rudoped $\mathrm{Ca}_{3} \mathrm{Ti}_{2} \mathrm{O}_{7}$ is much smaller than that of $\mathrm{Ca}_{3} \mathrm{Ti}_{2} \mathrm{O}_{7}$ $(2.35 \mathrm{eV})$ because of the presence of impurity energy level. As can be seen from the DOS, the band tail in the valence band spectrum is composed of impurity levels.

Interestingly, the spin-up and spin-down DOS become asymmetric in Fig. 7(b), thereby resulting in significant spin splitting, which indicates magnetic moments are induced due to $\mathrm{Ru}$ substitution. The total magnetic moments of different atoms are summarized in Table 2. It is obvious that the major contribution comes from $\mathrm{Ru}$ atom and partly derives from $\mathrm{O}$ and $\mathrm{Ru}$ atom hybridization. To understand the origin of the magnetic moments, the DOS of $\mathrm{Ru}^{4+}$ in $\mathrm{RuO}_{2}$ and $\mathrm{Ru}$-doped $\mathrm{Ca}_{3} \mathrm{Ti}_{2} \mathrm{O}_{7}$ are also shown in Figs. 7(c) and 7(d) respectively. $\mathrm{Ru}^{4+}$ of $\mathrm{RuO}_{2}$ is a non-spin polarizer, while in $\mathrm{Ru}$ substitution systems, the originally non-polarized $\mathrm{Ru}^{4+} \quad 4 \mathrm{~d}$ orbitals produce spin polarization due to orbital hybridization with the surrounding $\mathrm{O}$ atoms.
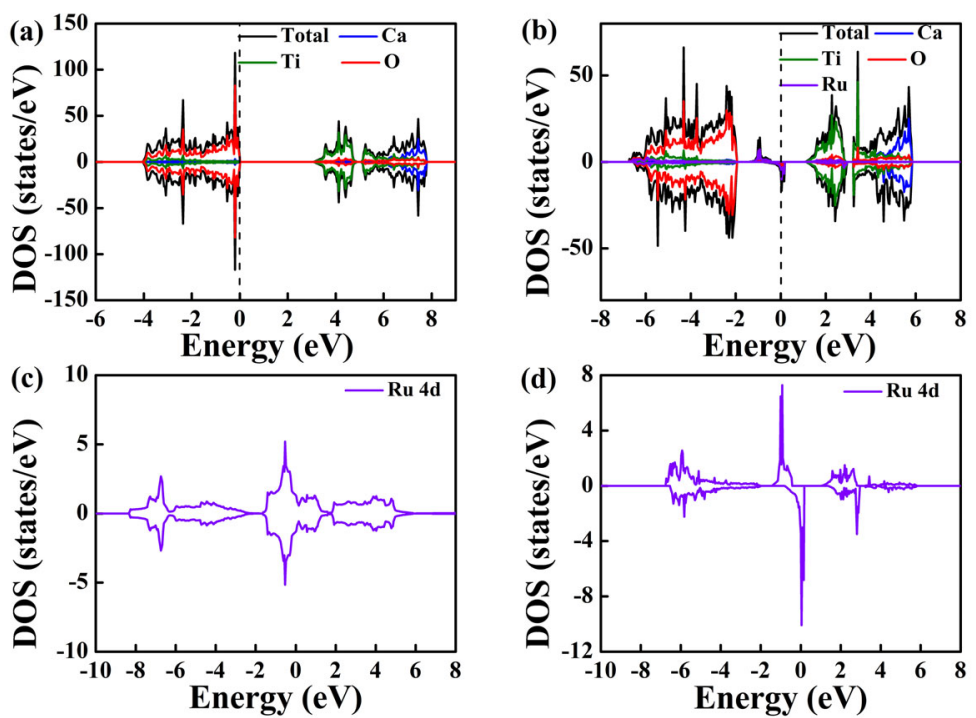

Fig. 7 DOS of (a) pure $\mathrm{Ca}_{3} \mathrm{Ti}_{2} \mathrm{O}_{7}$, (b) Ru-doped $\mathrm{Ca}_{3} \mathrm{Ti}_{2} \mathrm{O}_{7}$; DOS of $\mathrm{Ru}^{4+}$ in (c) $\mathrm{RuO}_{2}$ and (d) $\mathrm{Ru}$-doped $\mathrm{Ca}_{3} \mathrm{Ti}_{2} \mathrm{O}_{7}$.

Table 2 Contributions of magnetic moment from each atom

\begin{tabular}{ccccccccccc}
\hline Atom & $\mathrm{Ru}$ & $\mathrm{O}_{\mathrm{I}}$ & $\mathrm{O}_{\text {II }}$ & $\mathrm{O}_{\text {III }}$ & $\mathrm{O}_{\text {IV }}$ & $\mathrm{O}_{\mathrm{V}}$ & $\mathrm{O}_{\text {VI }}$ & $\mathrm{O}_{\text {VII }}$ & Ti & Total \\
\hline$M\left(\mu_{\mathrm{B}}\right)$ & 1.37 & 0.02 & 0.06 & 0.06 & 0.11 & 0.05 & 0.05 & 0.09 & -0.01 & 1.80 \\
\hline
\end{tabular}



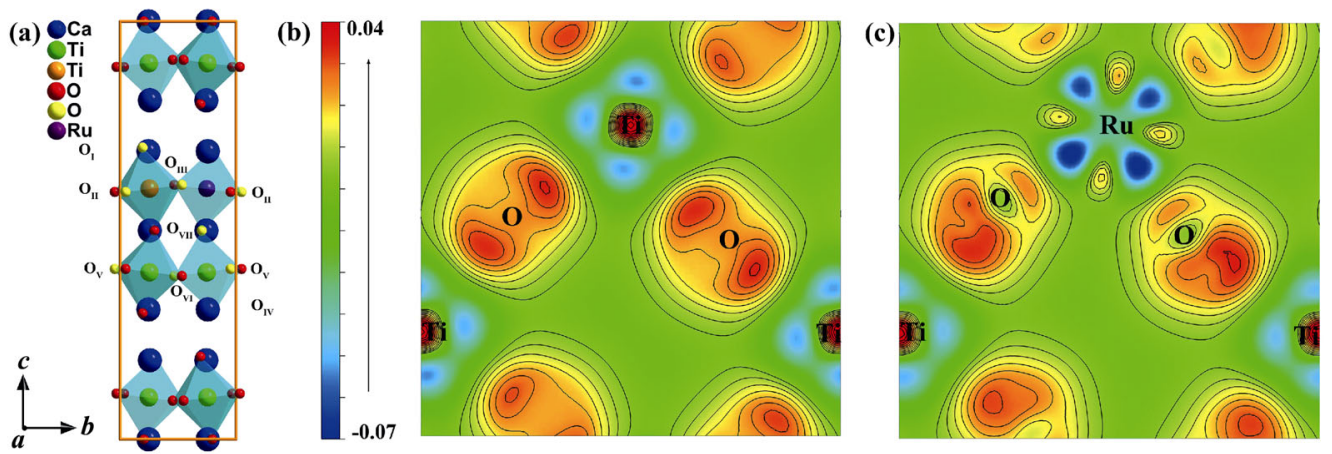

Fig. 8 (a) Model of magnetic moment distribution, where yellow, orange, and violet atoms represent magnetic moment produced by $\mathrm{O}, \mathrm{Ti}$, and $\mathrm{Ru}$ atoms, respectively. The charge density difference of the stable interface along (010) plane for (b) $\mathrm{Ca}_{3} \mathrm{Ti}_{2} \mathrm{O}_{7}$ and (c) Ru-doped $\mathrm{Ca}_{3} \mathrm{Ti}_{2} \mathrm{O}_{7}$. The red and blue colors represent charge accumulation and depletion respectively.

\subsubsection{Differential charge density studies}

In order to further explore the bonding properties between $\mathrm{Ti}$ and $\mathrm{O}$ atoms upon $\mathrm{Ru}$ doping, differential charge density of the plane (010) was plotted in Figs. 8(b) and $8(c)$. Increased charge concentration around oxygen atoms near the titanium atom was found after Ru doping, which reflects that the ionic character is slightly enhanced for the Ti-O bonds and the concentration of oxygen vacancies is higher after $\mathrm{Ru}$ doping. These results are consistent with those of XPS.

The materials with $\mathrm{Ru}$ doping render the room temperature multiferroic possible and can be applied more readily in low-power-consumption spintronics devices [40].

\section{Conclusions}

To summarize, $\mathrm{Ca}_{3} \mathrm{Ti}_{2} \mathrm{O}_{7}$ and $\mathrm{Ca}_{3} \mathrm{Ti}_{1.9} \mathrm{Ru}_{0.1} \mathrm{O}_{7}$ ceramics were successfully prepared by conventional solid-state techniques. The difference of ionic radius between titanium and ruthenium gives rise to the increasing degree of oxygen octahedral tilting and rotation. The decrease of the coercive field was owing to the increase of the oxygen vacancy concentration and grain growth. On the other hand, the introduction of oxygen vacancy increased the leakage current significantly. Optical properties such as size and location of band gaps were obtained by UV-vis measurements and first-principles calculations. Both experimental and theoretical results showed that the band gap is much smaller in $\mathrm{Ca}_{3} \mathrm{Ti}_{1.9} \mathrm{Ru}_{0.1} \mathrm{O}_{7}$ compared with $\mathrm{Ca}_{3} \mathrm{Ti}_{2} \mathrm{O}_{7}$, which is due to the hybridization of oxygen and ruthenium atoms after doping. At the same time, the B-site substitution of $\mathrm{Ru}$ element induces weak ferromagnetism, which is of great significance as it broadens the applications of the RP-perovskites.

\section{Acknowledgements}

This work was funded by the National Natural Science Foundation of China (51572193), and the Natural Science Foundation of Tianjin (20JCZDJC00210).

\section{References}

[1] Benedek NA, Fennie CJ. Hybrid improper ferroelectricity: A mechanism for controllable polarization-magnetization coupling. Phys Rev Lett 2011, 106: 107204.

[2] Bousquet E, Dawber M, Stucki N, et al. Improper ferroelectricity in perovskite oxide artificial superlattices. Nature 2008, 452: 732-736.

[3] Oh YS, Luo X, Huang FT, et al. Experimental demonstration of hybrid improper ferroelectricity and the presence of abundant charged walls in $\left(\mathrm{Ca}, \mathrm{Sr}_{3}\right)_{3} \mathrm{Ti}_{2} \mathrm{O}_{7}$ crystals. Nat Mater 2015, 14: 407-413.

[4] Glazer AM. The classification of tilted octahedra in perovskites. Acta Crystallogr B 1972, 28: 3384-3392.

[5] Liu XQ, Wu JW, Shi XX, et al. Hybrid improper ferroelectricity in Ruddlesden-Popper $\mathrm{Ca}_{3}(\mathrm{Ti}, \mathrm{Mn})_{2} \mathrm{O}_{7}$ ceramics. Appl Phys Lett 2015, 106: 202903.

[6] Ruddlesden SN, Popper P. The compound $\mathrm{Sr}_{3} \mathrm{Ti}_{2} \mathrm{O}_{7}$ and its structure. Acta Cryst 1958, 11: 54-55.

[7] Mulder AT, Benedek NA, Rondinelli JM, et al. Turning $\mathrm{ABO}_{3}$ antiferroelectrics into ferroelectrics: Design rules for practical rotation-driven ferroelectricity in double perovskites and $\mathrm{A}_{3} \mathrm{~B}_{2} \mathrm{O}_{7}$ Ruddlesden-Popper compounds. Adv Funct Mater 2013, 23: 4810-4820.

[8] Rondinelli JM, Fennie CJ. Octahedral rotation-induced ferroelectricity in cation ordered perovskites. Adv Mater 2012, 24: 1961-1968.

[9] Zhao HJ, Íñiguez J, Ren W, et al. Atomistic theory of hybrid improper ferroelectricity in perovskites. Phys Rev B 2014, 89: 174101.

[10] Oh YS, Luo X, Huang FT, et al. Experimental dem- 
onstration of hybrid improper ferroelectricity and the presence of abundant charged walls in $\left(\mathrm{Ca}, \mathrm{Sr}_{3}\right)_{3} \mathrm{Ti}_{2} \mathrm{O}_{7}$ crystals. Nat Mater 2015, 14: 407-413.

[11] Nowadnick EA, Fennie CJ. Domains and ferroelectric switching pathways in $\mathrm{Ca}_{3} \mathrm{Ti}_{2} \mathrm{O}_{7}$ from first principles. Phys Rev B 2016, 94: 104105.

[12] Senn MS, Bombardi A, Murray CA, et al. Negative thermal expansion in hybrid improper ferroelectric RuddlesdenPopper perovskites by symmetry trapping. Phys Rev Lett 2015, 114: 035701.

[13] Cherian JG, Birol T, Harms NC, et al. Optical spectroscopy and band gap analysis of hybrid improper ferroelectric $\mathrm{Ca}_{3} \mathrm{Ti}_{2} \mathrm{O}_{7}$. Appl Phys Lett 2016, 108: 262901.

[14] Li X, Yang L, Li CF, et al. Ultra-low coercive field of improper ferroelectric $\mathrm{Ca}_{3} \mathrm{Ti}_{2} \mathrm{O}_{7}$ epitaxial thin films. Appl Phys Lett 2017, 110: 042901.

[15] Okazaki Y, Mishima T, Nishimoto S, et al. Photocatalytic activity of $\mathrm{Ca}_{3} \mathrm{Ti}_{2} \mathrm{O}_{7}$ layered-perovskite doped with $\mathrm{Rh}$ under visible light irradiation. Mater Lett 2008, 62: 3337 3340.

[16] Cao RP, Chen G, Yu XG, et al. Luminescence properties of $\mathrm{Ca}_{3} \mathrm{Ti}_{2} \mathrm{O}_{7}: \mathrm{Eu}^{3+}, \mathrm{Bi}^{3+}, \mathrm{R}^{+}\left(\mathrm{R}^{+}=\mathrm{Li}^{+}, \mathrm{Na}^{+}\right.$, and $\left.\mathrm{K}^{+}\right)$red emission phosphor. J Solid State Chem 2014, 220: 97-101.

[17] Li CF, Zheng SH, Wang HW, et al. Structural transitions in hybrid improper ferroelectric $\mathrm{Ca}_{3} \mathrm{Ti}_{2} \mathrm{O}_{7}$ tuned by site-selective isovalent substitutions: A first-principles study. Phys Rev B 2018, 97: 184105.

[18] Huang C, Wong-Ng W, Liu WF, et al. Major improvement of ferroelectric and optical properties in Na-doped Ruddlesden-Popper layered hybrid improper ferroelectric compound, $\mathrm{Ca}_{3} \mathrm{Ti}_{2} \mathrm{O}_{7}$. J Alloys Compd 2019, 770: 582-588.

[19] Liu XQ, Chen BH, Lu JJ, et al. Hybrid improper ferroelectricity in B-site substituted $\mathrm{Ca}_{3} \mathrm{Ti}_{2} \mathrm{O}_{7}$ : The role of tolerance factor. Appl Phys Lett 2018, 113: 242904.

[20] Gong YF, Wu P, Hai X, et al. Enhanced dielectric and magnetic properties in $\mathrm{Ru}$-substituted $\mathrm{Bi}_{0.9} \mathrm{La}_{0.1} \mathrm{FeO}_{3}$ ceramics. J Phys D: Appl Phys 2012, 45: 355001.

[21] Xu XL, Liu WF, Zhang H, et al. The abnormal electrical and optical properties in $\mathrm{Na}$ and $\mathrm{Ni}$ codoped $\mathrm{BiFeO}_{3}$ nanoparticles. J Appl Phys 2015, 117: 174106.

[22] Li GJ, Liu XQ, Lu JJ, et al. Crystal structural evolution and hybrid improper ferroelectricity in Ruddlesden-Popper $\mathrm{Ca}_{3-x} \mathrm{Sr}_{x} \mathrm{Ti}_{2} \mathrm{O}_{7}$ ceramics. J Appl Phys 2018, 123: 014101.

[23] Yan F, Lai M-O, Lu L, et al. Enhanced multiferroic properties and valence effect of $\mathrm{Ru}$-doped $\mathrm{BiFeO}_{3}$ thin films. J Phys Chem C 2010, 114: 6994-6998.

[24] $\mathrm{Yu} \mathrm{K}$, Jin L, Li Y, et al. Structure and conductivity of perovskite $\mathrm{Li}_{0.355} \mathrm{La}_{0.35} \mathrm{Sr}_{0.3} \mathrm{Ti}_{0.995} \mathrm{M} 0.005 \mathrm{O}_{3}(\mathrm{M}=\mathrm{Al}$, Co and In) ceramics. Ceram Int 2019, 45: 23941-23947.

[25] $\mathrm{Hu} \mathrm{ZZ}, \mathrm{Lu} J J$, Chen BH, et al. First-order phase transition and unexpected rigid rotation mode in hybrid improper ferroelectric ( $\mathrm{La}, \mathrm{Al}$ ) co-substituted $\mathrm{Ca}_{3} \mathrm{Ti}_{2} \mathrm{O}_{7}$ ceramics. $J$ Materiomics 2019, 5: 618-625.

[26] Jin L, Li F, Zhang SJ. Decoding the fingerprint of ferroelectric loops: Comprehension of the material properties and structures. J Am Ceram Soc 2014, 97: 1-27.

[27] Yan HX, Inam F, Viola G, et al. The contribution of electrical conductivity, dielectric permittivity and domain switching in ferroelectric hysteresis loops. J Adv Dielect
2011, 1: 107-118.

[28] Li JY, Rogan RC, Üstündag E, et al. Domain switching in polycrystalline ferroelectric ceramics. Nat Mater 2005, 4: 776-781.

[29] Zhang $\mathrm{BH}, \mathrm{Hu} \mathrm{ZZ}$, Chen $\mathrm{BH}$, et al. Improved hybrid improper ferroelectricity in B-site substituted $\mathrm{Ca}_{3} \mathrm{Ti}_{2} \mathrm{O}_{7}$ ceramics with a Ruddlesden-Popper structure. J Appl Phys 2020, 128: 054102.

[30] Zhang QW, Cai W, Li QT, et al. Enhanced piezoelectric response of $(\mathrm{Ba}, \mathrm{Ca})(\mathrm{Ti}, \mathrm{Zr}) \mathrm{O}_{3}$ ceramics by super large grain size and construction of phase boundary. J Alloys Compd 2019, 794: 542-552.

[31] Han YL, Liu WF, Wu P, et al. Effect of aliovalent Pd substitution on multiferroic properties in $\mathrm{BiFeO}_{3}$ nanoparticles. J Alloys Compd 2016, 661: 115-121.

[32] Zhang XN, Liu WF, Han YL, et al. Novel optical and magnetic properties of $\mathrm{Li}$-doped quasi-2D manganate $\mathrm{Ca}_{3} \mathrm{Mn}_{2} \mathrm{O}_{7}$ particles. J Mater Chem C 2017, 5: 7011-7019.

[33] Dupin J-C, Gonbeau D, Vinatier P, et al. Systematic XPS studies of metal oxides, hydroxides and peroxides. Phys Chem Chem Phys 2000, 2: 1319-1324.

[34] Mukhopadhyay SM, Chen TS. Interaction of $\mathrm{PbZr}_{x} \mathrm{Ti}_{1-x} \mathrm{O}_{3}$ (PZT) with Ni: Role of surface defects. J Phys D: Appl Phys 1995, 28: 2170-2175.

[35] Miller RC, Weinreich G. Mechanism for the sidewise motion of $180^{\circ}$ domain walls in barium titanate. Phys Rev 1960, 117: 1460-1466.

[36] Noto LL, Pitale SS, Terblans JJ, et al. Surface chemical changes of $\mathrm{CaTiO}_{3}: \mathrm{Pr}^{3+}$ upon electron beam irradiation. Phys B: Condens Matter 2012, 407: 1517-1520.

[37] Naldoni A, Allieta M, Santangelo S, et al. Effect of nature and location of defects on bandgap narrowing in black $\mathrm{TiO}_{2}$ nanoparticles. J Am Chem Soc 2012, 134: 7600-7603.

[38] Han YL, Liu WF, Xu XL, et al. The abnormal optical property and room-temperature exchange bias behavior in $\mathrm{Na}-$ and $\mathrm{Ru}$-codoped $\mathrm{BiFeO}_{3}$ nanoparticles. $J$ Am Ceram Soc 2016, 99: 3616-3622.

[39] Lu CL, Chen X, Dong S, et al. Ru-doping-induced ferromagnetism in charge-ordered $\mathrm{La}_{0.4} \mathrm{Ca}_{0.6} \mathrm{MnO}_{3}$. Phys Rev $B$ 2009, 79: 245105 .

[40] Tokunaga Y, Furukawa N, Sakai H, et al. Composite domain walls in a multiferroic perovskite ferrite. Nat Mater 2009, 8: 558-562.

Open Access This article is licensed under a Creative Commons Attribution 4.0 International License, which permits use, sharing, adaptation, distribution and reproduction in any medium or format, as long as you give appropriate credit to the original author(s) and the source, provide a link to the Creative Commons licence, and indicate if changes were made.

The images or other third party material in this article are included in the article's Creative Commons licence, unless indicated otherwise in a credit line to the material. If material is not included in the article's Creative Commons licence and your intended use is not permitted by statutory regulation or exceeds the permitted use, you will need to obtain permission directly from the copyright holder.

To view a copy of this licence, visit http://creativecommons.org/licenses/by/4.0/. 